Document downloaded from:

http://hdl.handle.net/10251/143615

This paper must be cited as:

Amiri, A.; Cordero Barbero, A.; Darvishi, M.; Torregrosa Sánchez, JR. (01-0). Preserving the order of convergence: Low-complexity Jacobian-free iterative schemes for solving nonlinear systems. Journal of Computational and Applied Mathematics. 337:87-97. https://doi.org/10.1016/j.cam.2018.01.004

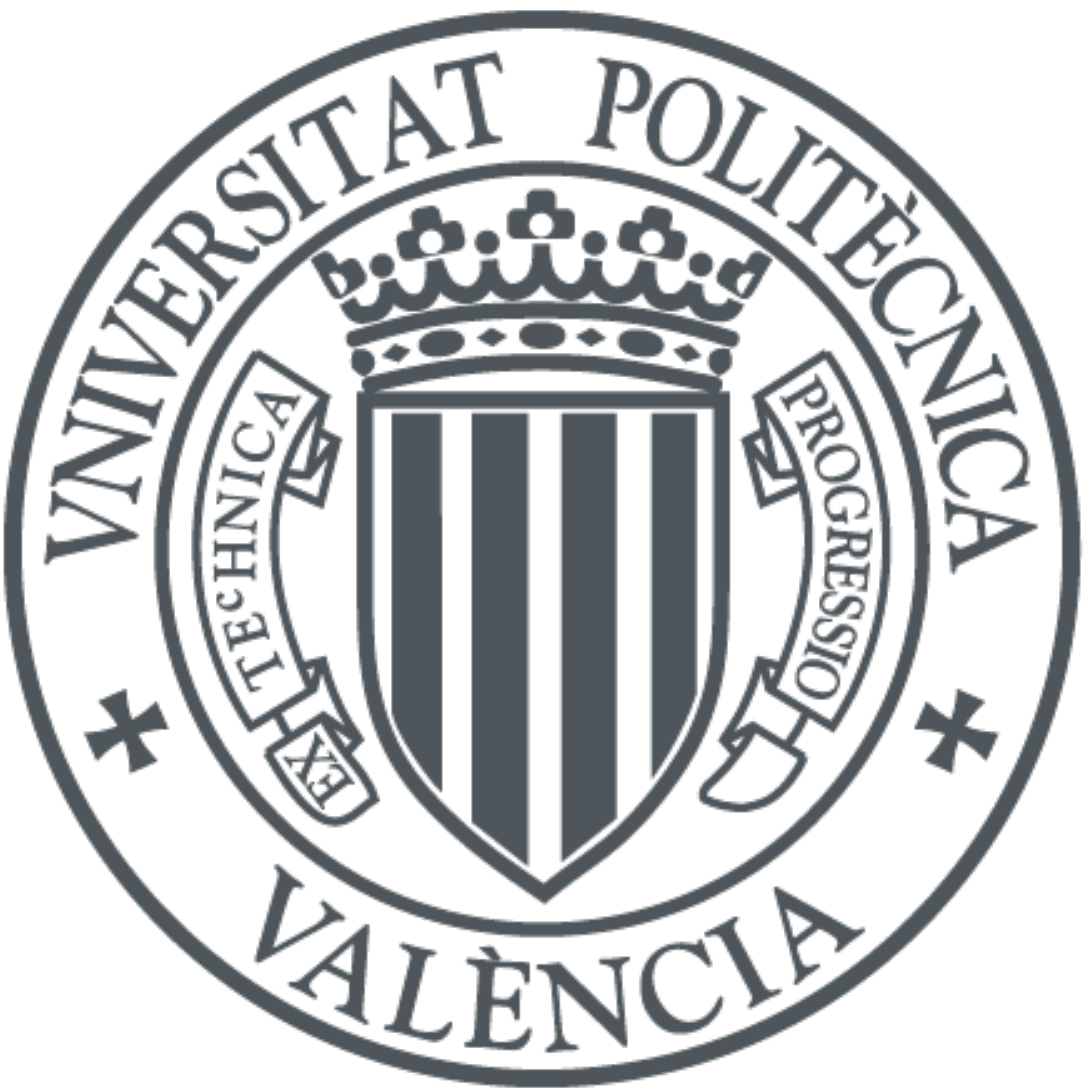

The final publication is available at

https://doi.org/10.1016/j.cam.2018.01.004

Copyright Elsevier

Additional Information 


\title{
Preserving the order of convergence: low-complexity Jacobian-free iterative schemes for solving nonlinear systems th
}

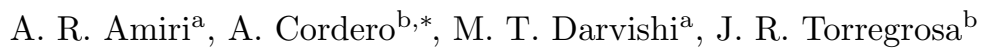 \\ ${ }^{a}$ Department of Mathematics, Razi University, Iran \\ ${ }^{b}$ Instituto de Matemáticas Multidisciplinar, Universitat Politècnica de València, Spain
}

\begin{abstract}
In this paper, a new technique to construct a family of divided differences for designing derivative-free iterative methods for solving nonlinear systems is proposed. By using these divided differences any kind of iterative methods containing a Jacobian matrix in its iterative expression can be transformed into a "Jacobian-free" scheme preserving the order of convergence. This procedure is applied on different schemes, showing theoretically their order and error equation. Numerical experiments confirm the theoretical results and show the efficiency and performance of the new Jacobian-free schemes.
\end{abstract}

Keywords: Nonlinear system of equations, iterative method, Jacobian-free scheme, divided difference, order of convergence.

\section{Introduction}

Nonlinear systems are of interest to engineers, physicists, mathematicians and other scientists, because the modelization of many nonlinear problems arising in different fields of science is made by means of a nonlinear system of equations.

Let $F(x)=0$ be a system of nonlinear equations, where $F: D \subseteq \mathbb{R}^{n} \longrightarrow \mathbb{R}^{n}$ and $f_{i}, i=1,2, \ldots, n$, are the coordinate functions of $F, F(x)=\left(f_{1}(x), f_{2}(x), \ldots, f_{n}(x)\right)^{T}$. Nonlinear systems are difficult to solve, the solution $\bar{x}$ usually is obtained by linearizing the nonlinear problem or using a fixed point function $G: D \subseteq \mathbb{R}^{n} \longrightarrow \mathbb{R}^{n}$, which leads to a fixed point iteration scheme. There are many finding-root methods for systems of nonlinear equations. The most famous one is the second order Newton method,

$$
x^{(k+1)}=x^{(k)}-\left[F^{\prime}\left(x^{(k)}\right)\right]^{-1} F\left(x^{(k)}\right),
$$

where $F^{\prime}\left(x^{(k)}\right)$ is the Jacobian matrix of $F$ evaluated at $k$ th iteration.

In recent decades, many authors have tried to design iterative procedures with better efficiency and higher order of convergence than Newton's scheme (see, for example, [1, 2, 3, 4, 5, 6, 7, 8, 9, 10, and the references therein). Most of them need to evaluate the Jacobian matrix at one or more points per iteration. One of the difficulties of using these methods is the computation of the Jacobian matrix, that in some cases, may 15 not exist, or when it exists, for high dimensional cases, computing the Jacobian matrix is too costly or even in some cases unviable. Therefore, some authors have tried to omit the Jacobian matrix, replacing it by a divided difference operator. The simplest one is Steffensen's scheme [11, obtained by replacing the Jacobian matrix in Newton's method by a first-order divided difference, preserving the second order of convergence,

$$
x^{(k+1)}=x^{(k)}-\left[z^{(k)}, x^{(k)} ; F\right]^{-1} F\left(x^{(k)}\right),
$$

\footnotetext{
This research was partially supported by Ministerio de Economía y Competitividad MTM2014-52016-C2-2-P, MTM201564013-P and Generalitat Valenciana PROMETEO/2016/089.

* Corresponding author

Email address: acordero@mat.upv.es (A. Cordero)
} 
where $z^{(k)}=x^{(k)}+F\left(x^{(k)}\right)$, being $[\cdot, \cdot ; F]: \Omega \times \Omega \subset \mathbb{R}^{n} \times \mathbb{R}^{n} \longrightarrow \mathcal{L}\left(\mathbb{R}^{n}\right)$ the divided difference operator of ${ }_{20} \quad F$ on $\mathbb{R}^{n}$ defined as (see [1])

$$
[x, y ; F](x-y)=F(x)-F(y), \text { for any } x, y \in \Omega .
$$

Despite both Newton an Steffensen schemes have quadratic convergence, it has been proved that the stability of Steffensen'method, defined as the dependence on the initial estimation, is very bad compared with that of Newton one. This was analyzed in [12] and in [13, proving that, in the scalar case $f(x)=0$, the stability of the iterative schemes without derivatives was improved when $z=x+\gamma f(x)$ for small values of $\gamma$. A different approach for improving the stability of derivative-free methods was imtroduced by Amat et al. in [14]

Nevertheless, one of the problems of replacing Jacobian matrices by divided-differences is that, in many iterative methods, the new derivative-free scheme has not the same order as the initial one. For example, let us consider the multidimensional extension of the fourth-order Ostrowski's method [15, 16, 17.

$$
\begin{aligned}
y^{(k)} & =x^{(k)}-\left[F^{\prime}\left(x^{(k)}\right)\right]^{-1} F\left(x^{(k)}\right), \\
x^{(k+1)} & =y^{(k)}-\left[2\left[x^{(k)}, y^{(k)} ; F\right]-F^{\prime}\left(x^{(k)}\right)\right]^{-1} F\left(y^{(k)}\right),
\end{aligned}
$$

that reaches cubic convergence when $F^{\prime}\left(x^{(k)}\right)$ is replaced by the non-symmetric kind of divided difference (2). Also, many other fourth order methods do not preserve the order of convergence, such as Jarratt's [18 scheme

$$
\begin{aligned}
y^{(k)} & =x^{(k)}-\frac{2}{3}\left[F^{\prime}\left(x^{(k)}\right)\right]^{-1} F\left(x^{(k)}\right), \\
x^{(k+1)} & =x^{(k)}-J\left(x^{(k)}\right)\left[F^{\prime}\left(x^{(k)}\right)\right]^{-1} F\left(x^{(k)}\right),
\end{aligned}
$$

where $J\left(x^{(k)}\right)=\left[6 F^{\prime}\left(y^{(k)}\right)-2 F^{\prime}\left(x^{(k)}\right)\right]^{-1}\left[3 F^{\prime}\left(y^{(k)}\right)+F^{\prime}\left(x^{(k)}\right)\right]$, fourth-order Sharma's method [19], denoted by $\mathrm{M}_{4,3}$,

$$
\begin{aligned}
y^{(k)} & =x^{(k)}-\left[F^{\prime}\left(x^{(k)}\right)\right]^{-1} F\left(x^{(k)}\right), \\
x^{(k+1)} & =y^{(k)}-\left[3 I-2\left[F^{\prime}\left(x^{(k)}\right)\right]^{-1}\left[x^{(k)}, y^{(k)} ; F\right]\right]\left[F^{\prime}\left(x^{(k)}\right)\right]^{-1} F\left(y^{(k)}\right),
\end{aligned}
$$

Montazeri et al. 20] fourth-order method,

$$
\begin{aligned}
y^{(k)} & =x^{(k)}-\frac{2}{3}\left[F^{\prime}\left(x^{(k)}\right)\right]^{-1} F\left(x^{(k)}\right), \\
x^{(k+1)} & =x^{(k)}-\left[\frac{23}{8} I-3\left[F^{\prime}\left(x^{(k)}\right)\right]^{-1} F^{\prime}\left(y^{(k)}\right)+\frac{9}{8}\left(\left[F^{\prime}\left(x^{(k)}\right)\right]^{-1} F^{\prime}\left(y^{(k)}\right)\right)^{2}\right]\left[F^{\prime}\left(x^{(k)}\right)\right]^{-1} F\left(x^{(k)}\right),
\end{aligned}
$$

and Hueso et al. 21] iterative scheme,

$$
\begin{aligned}
y^{(k)} & =x^{(k)}-\frac{2}{3}\left[F^{\prime}\left(x^{(k)}\right)\right]^{-1} F\left(x^{(k)}\right), \\
x^{(k+1)} & =x^{(k)}-\left[-\frac{1}{2} I+\frac{9}{8} F^{\prime}\left(x^{(k)}\right)\left[F^{\prime}\left(y^{(k)}\right)\right]^{-1}+\frac{3}{8}\left[F^{\prime}\left(x^{(k)}\right)\right]^{-1} F^{\prime}\left(y^{(k)}\right)\right]\left[F^{\prime}\left(x^{(k)}\right)\right]^{-1} F\left(x^{(k)}\right),
\end{aligned}
$$

which is a fourth-order iterative method and is denoted originally as $\mathrm{M1}_{4}$. All of them are examples of iterative schemes that never preserve the order of convergence when a non-symmetric divided difference (2) is used as an approximation of the Jacobian matrix.

In the same way, an example of sixth-order iterative method that does not preserve the order of convergence by replacing the Jacobian matrices by divided difference [2], is Sharma's scheme [19], denoted by 
$\mathrm{M}_{6,3}$ whose iterative expression is

$$
\begin{aligned}
y^{(k)} & =x^{(k)}-\left[F^{\prime}\left(x^{(k)}\right)\right]^{-1} F\left(x^{(k)}\right), \\
z^{(k)} & =y^{(k)}-\left[3 I-2\left[F^{\prime}\left(x^{(k)}\right)\right]^{-1}\left[x^{(k)}, y^{(k)} ; F\right]\right]\left[F^{\prime}\left(x^{(k)}\right)\right]^{-1} F\left(y^{(k)}\right), \\
x^{(k+1)} & =z^{(k)}-\left[3 I-2\left[F^{\prime}\left(x^{(k)}\right)\right]^{-1}\left[x^{(k)}, y^{(k)} ; F\right]\right]\left[F^{\prime}\left(x^{(k)}\right)\right]^{-1} F\left(z^{(k)}\right) .
\end{aligned}
$$

Some examples of eighth order iterative methods whose order of convergence decrease when Jacobian matrices are replaced by divided differences as (2) are: Sharma and Arora [22] eighth-order method with three steps that is denoted by $\mathrm{NLM}_{8}$,

$$
\begin{aligned}
y^{(k)} & =x^{(k)}-\left[F^{\prime}\left(x^{(k)}\right)\right]^{-1} F\left(x^{(k)}\right), \\
z^{(k)} & =y^{(k)}-\left[\frac{13}{4} I-H\left(x^{(k)}\right)\left(\frac{7}{2} I-\frac{5}{4} H\left(x^{(k)}\right)\right)\right]\left[F^{\prime}\left(x^{(k)}\right)\right]^{-1} F\left(y^{(k)}\right), \\
x^{(k+1)} & =z^{(k)}-\left[\frac{7}{2} I-H\left(x^{(k)}\right)\left(4 I-\frac{3}{2} H\left(x^{(k)}\right)\right)\right]\left[F^{\prime}\left(x^{(k)}\right)\right]^{-1} F\left(z^{(k)}\right),
\end{aligned}
$$

where $H\left(x^{(k)}\right)=\left[F^{\prime}\left(x^{(k)}\right)\right]^{-1} F^{\prime}\left(y^{(k)}\right)$. Also, two eighth-order methods from Cordero et al. in [23; the first one is described as

$$
\begin{aligned}
y^{(k)} & =x^{(k)}-\left[F^{\prime}\left(x^{(k)}\right)\right]^{-1} F\left(x^{(k)}\right), \\
z^{(k)} & =y^{(k)}-\left[\frac{5}{4} I-\frac{1}{2}\left[F^{\prime}\left(y^{(k)}\right)\right]^{-1} F^{\prime}\left(x^{(k)}\right)+\frac{1}{4}\left(\left[F^{\prime}\left(y^{(k)}\right)\right]^{-1} F^{\prime}\left(x^{(k)}\right)\right)^{2}\right]\left[F^{\prime}\left(y^{(k)}\right)\right]^{-1} F\left(y^{(k)}\right), \\
x^{(k+1)} & =z^{(k)}-\left[\frac{3}{2} I-\left[F^{\prime}\left(y^{(k)}\right)\right]^{-1} F^{\prime}\left(x^{(k)}\right)+\frac{1}{2}\left(\left[F^{\prime}\left(y^{(k)}\right)\right]^{-1} F^{\prime}\left(x^{(k)}\right)\right)^{2}\right]\left[F^{\prime}\left(y^{(k)}\right)\right]^{-1} F\left(z^{(k)}\right),
\end{aligned}
$$

and it is denoted by CCGT1, and second one, denoted by CCGT2, is defined as

$$
\begin{aligned}
y^{(k)} & =x^{(k)}-\left[F^{\prime}\left(x^{(k)}\right)\right]^{-1} F\left(x^{(k)}\right), \\
z^{(k)} & =y^{(k)}-\left[\frac{1}{4} I+\frac{1}{2}\left[F^{\prime}\left(y^{(k)}\right)\right]^{-1} F^{\prime}\left(x^{(k)}\right)+\frac{1}{4}\left(\left[F^{\prime}\left(y^{(k)}\right)\right]^{-1} F^{\prime}\left(x^{(k)}\right)\right)^{2}\right]\left[F^{\prime}\left(x^{(k)}\right)\right]^{-1} F\left(y^{(k)}\right), \\
x^{(k+1)} & =z^{(k)}-\left[\frac{1}{2} I+\frac{1}{2}\left(\left[F^{\prime}\left(y^{(k)}\right)\right]^{-1} F^{\prime}\left(x^{(k)}\right)\right)^{2}\right]\left[F^{\prime}\left(x^{(k)}\right)\right]^{-1} F\left(z^{(k)}\right) .
\end{aligned}
$$

On the other hand, Cordero et al. in [24] proposed to use, for scalar functions $f: D \subseteq \mathbb{R} \longrightarrow \mathbb{R}$, the divided difference $f^{\prime}\left(x_{k}\right) \approx \frac{f\left(z_{k}\right)-f\left(x_{k}\right)}{z_{k}-x_{k}}$ with $z_{k}=x_{k}+\gamma f\left(x_{k}\right)^{m}$, for preserving the order of convergence of an optimal iterative method of order $2^{r}$, it is necessary to use $m \geq r$.

In this paper, we prove that if $[x, x+G(x) ; F]$ is used as estimation of the Jacobian matrix, where $G: D \subseteq$ $\mathbb{R}^{n} \longrightarrow \mathbb{R}^{n}$ such that $G(x)=\left(f_{1}^{m}(x), f_{2}^{m}(x), \ldots, f_{n}^{m}(x)\right)^{T}$ then, the divided difference is an approximation of 40 order $m$ of the Jacobian matrix of function $F(x)$ at the point $x$. Also we show that by choosing suitable $m$, the order of convergence of any iterative method can be preserved, when we replace the Jacobian matrix by this estimation. Therefore, this result extend to the multidimensional case that obtained by the authors in [24].

The rest of paper is organized as follows: In Section 2, the order of the new approximations of the Jacobian 45 matrix are investigated and some properties are proved. In Section 3, we apply these divided differences on some iterative methods and prove their order of the convergence when these Jacobian approximations are used. Finally, in Section 4 we present some numerical results to show the efficiency and performance of the new Jacobian-free schemes. 


\section{Development of divided differences with desirable order}

In this section, we show that the non-symmetric divided difference $[x, x+G(x) ; F]$ is an approximation of order $m$ of the Jacobian matrix $F^{\prime}(x)$. In order to get this aim, we firstly need to introduce some preliminaries: the following notation can be found in 25, but we introduce it in the following for the sake of completeness. Let $F: D \subseteq \mathbb{R}^{n} \longrightarrow \mathbb{R}^{n}$ be sufficiently Fréchet differentiable in $D$. The $q$ th derivative of $F$ at $u \in \mathbb{R}^{n}$ is the $q$-linear function $F^{(q)}(u): \mathbb{R}^{n} \times \ldots \times \mathbb{R}^{n} \longrightarrow \mathbb{R}^{n}$ such that $F^{(q)}(u)\left(v_{1}, \ldots, v_{q}\right) \in \mathbb{R}^{n}$. It is 55 easy to observe that

1) $F^{(q)}(u)\left(v_{1}, \ldots, v_{q-1}, \cdot\right) \in \mathcal{L}\left(\mathbb{R}^{n}\right)$.

2) $F^{(q)}(u)\left(v_{\sigma_{1}}, \ldots, v_{\sigma_{q}}\right)=F^{(q)}(u)\left(v_{1}, \ldots, v_{q}\right)$, for any permutation $\sigma$ of $\{1,2, \ldots, q\}$.

From these properties, we can use the following notation:

i) $F^{(q)}(u)\left(v_{1}, \ldots, v_{q}\right)=F^{(q)}(u) v_{1} \cdots v_{q}$.

ii) $F^{(q)}(u) v^{q-1} F^{(p)}(u) v^{p}=F^{(q)}(u) F^{(p)}(u) v^{q+p-1}$.

So, by using the previous expressions, we can write the Taylor expansion of $F$ around solution $\bar{x}$ of $F(x)=0$, when the Jacobian $F^{\prime}(\bar{x})$ is nonsingular, as follows

$$
F(x)=F^{\prime}(\bar{x})\left(e+\sum_{q=2}^{p-1} C_{q} e^{q}\right)+O\left(e^{p}\right)
$$

where $e=x-\bar{x}$ and, for $l \geq 1$,

$$
F^{(l)}(x)=F^{\prime}(\bar{x})\left(\sum_{k=l}^{p-1} \frac{k !}{(k-l) !} C_{k} e^{k-l}\right)+O\left(e^{p-l}\right),
$$

where $C_{1}=I$ and $C_{q}=\frac{1}{q !}\left[F^{\prime}(\bar{x})\right]^{-1} F^{(q)}(\bar{x}), q \geq 2$. In this paper, we use the notation $\mathcal{L}_{q}\left(\mathbb{R}^{n}, \mathbb{R}^{n}\right)$ instead 65 of $\mathcal{L}(\overbrace{\mathbb{R}^{n} \times \ldots \times \mathbb{R}^{n}}^{q \text { times }})$, for compactness.

The formula of Gennochi-Hermite (see [11])

$$
[x+h, x ; F]=\int_{0}^{1} F^{\prime}(x+t h) d t, \quad \forall x, h \in D \subset \mathbb{R}^{n},
$$

allows us to calculate the Taylor expansion of the divided difference operator in terms of the successive derivatives of $F$,

$$
[x+h, x ; F]=\sum_{j=0}^{p} \frac{1}{(j+1) !} F^{(j+1)}(x) h^{j}+O\left(h^{p+1}\right), \quad \forall x, h \in D .
$$

By denoting $y=x+h$ and using the error at both points, $e=x-\bar{x}, e_{y}=y-\bar{x}$, the Taylor expansion of the divided difference $(2)$ can be written as

$$
[y, x ; F]=F^{\prime}(\bar{x})\left[I+C_{2}\left(e_{y}+e\right)+C_{3}\left(e_{y}^{2}+e_{y} e+e^{2}\right)+C_{4}\left(e_{y}^{3}+e_{y}^{2} e+e_{y} e^{2}+e^{3}\right)+\ldots\right] .
$$

Now, we use these expressions to prove the following result.

Theorem 2.1. Let $F$ be a nonlinear operator $F: D \subseteq \mathbb{R}^{n} \longrightarrow \mathbb{R}^{n}$ with coordinate functions $f_{i}, i=$ $1,2, \ldots, n$ and $m \in \mathbb{R}$ such that $m \geq 1$. Let us consider the divided difference operator $[x+G(x), x ; F]$, where $G(x)=\left(f_{1}^{m}(x), f_{2}^{m}(x), \ldots, f_{n}^{m}(x)\right)^{T}$, then the order of the divided difference $[x+G(x), x ; F]$ as an approximation of the Jacobian matrix $F^{\prime}(x)$ is $m$. 
Proof. Let $g_{i}(x), i=0,1,2, \ldots$ be the coordinate functions of $G(x)$. Let us consider the Taylor expansion 75 of $g_{i}(x)$ around $\bar{x}$,

$$
\begin{aligned}
g_{i}(x)= & g_{i}(\bar{x})+\sum_{j_{1}=1}^{n} \frac{\partial g_{i}(\bar{x})}{\partial x_{j_{1}}} e_{j_{1}}+\sum_{j_{2}=1}^{n} \sum_{j_{1}=1}^{n} \frac{\partial^{2} g_{i}(\bar{x})}{\partial x_{j_{2}} \partial x_{j_{1}}} e_{j_{1}} e_{j_{2}}+\sum_{j_{3}=1}^{n} \sum_{j_{2}=1}^{n} \sum_{j_{1}=1}^{n} \frac{\partial^{3} g_{i}(\bar{x})}{\partial x_{j_{3}} \partial x_{j_{2}} \partial x_{j_{1}}} e_{j_{1}} e_{j_{2}} e_{j_{3}} \\
& +\ldots+\sum_{j_{l}=1}^{n} \ldots \sum_{j_{2}=1}^{n} \sum_{j_{1}=1}^{n} \frac{\partial^{r} g_{i}(\bar{x})}{\partial x_{j_{1}}^{r_{1}} \partial x_{j_{2}}^{r_{2}} \ldots \partial x_{j_{l}}^{r_{l}}} e_{j_{1}}^{r_{1}} e_{j_{2}}^{r_{2}} \ldots e_{j_{l}}^{r_{l}}+\ldots
\end{aligned}
$$

where $r_{s} \in\{1,2, \ldots, r\}$ for $s=1,2, \ldots, l$ and $r=r_{1}+r_{2}+\ldots+r_{l}, e=x-\bar{x}$ and $e_{j_{s}}=x_{j_{s}}-\bar{x}_{j_{s}}$, for $s=1,2, \ldots, l$ is the $j_{s}$ th coordinate of error $e$.

We can write $(9)$, as

$$
g_{i}(x)=A_{1}^{i} e+A_{2}^{i} e^{2}+\ldots+A_{m-1}^{i} e^{m-1}+A_{m}^{i} e^{m}+A_{m+1}^{i} e^{m+1}+\ldots,
$$

where $A_{t}^{i} \in \mathcal{L}_{i}\left(\mathbb{R}^{n}, \mathbb{R}^{n}\right)$ for $t=1,2, \ldots$

Since

$$
\frac{\partial^{r} g_{i}(\bar{x})}{\partial x_{j_{1}}^{r_{1}} \partial x_{j_{2}}^{r_{2}} \ldots \partial x_{j_{l}}^{r_{l}}}=m(m-1) \cdots(m-r+1) f_{i}^{m-r}(\bar{x}) \frac{\partial^{r} f_{i}(\bar{x})}{\partial x_{j_{1}}^{r_{1}} \partial x_{j_{2}}^{r_{2}}}=0, \quad \text { for all } r<m,
$$

so $A_{t}^{i}=0$ for $t=1,2, \ldots, m-1$ and we have

$$
g_{i}(x)=A_{m}^{i} e^{m}+A_{m+1}^{i} e^{m+1}+O\left(e^{m+2}\right) .
$$

By defining multilinear operator $A_{t}=\left[A_{t}^{1}, A_{t}^{2}, \ldots, A_{t}^{n}\right]$ for $t=1,2, \ldots$, the Taylor series of $G(x)$ around $\bar{x}$ can be written as

$$
G(x)=A_{m} e^{m}+A_{m+1} e^{m+1}+O\left(e^{m+2}\right),
$$

so we define the error at $y$ as

$$
e_{y}=y-\bar{x}=x+G(x)-\bar{x}=e+G(x) .
$$

85 Now let

$$
F(x)=F^{\prime}(\bar{x})\left[e+C_{2} e^{2}+C_{3} e^{3}+C_{4} e^{4}+C_{5} e^{5}+C_{6} e^{6}+C_{7} e^{7}\right]+O\left(e^{8}\right),
$$

be the Taylor expansion of $F(x)$ around $\bar{x}$. By applying Gennochi-Hermite formula (8), we have

$$
\begin{aligned}
{[y, x ; F]=} & F^{\prime}(\bar{x})\left[I+C_{2}\left(e_{y}+e\right)+C_{3}\left(e_{y}^{2}+e_{y} e+e^{2}\right)+C_{4}\left(e_{y}^{3}+e_{y}^{2} e+e_{y} e^{2}+e^{3}\right)+\ldots\right] \\
= & F^{\prime}(\bar{x})\left[I+2 C_{2} e+3 C_{3} e^{2}+\ldots+m C_{m} e^{m-1}+\left(C_{2} A_{m}+(m+1) C_{m+1}\right) e^{m}\right. \\
& \left.+\left(C_{2} A_{m+1}+C_{3} A_{m}+(m+2) C_{m+2}\right) e^{m+1}+\cdots\right]
\end{aligned}
$$

As the Taylor expansions of $F^{\prime}(x)$ and $[x, y ; F]$ around $\bar{x}$ coincide in the first $m$ terms, so the order of divided difference $[x+G(x), x ; F]$ is exactly $m$.

The following corollary can be obtained from the previous result.

90 Corollary 2.1. Under the same assumptions as in Theorem 2.1, the central divided difference operator $[x+G(x), x-G(x) ; F]$, where $G(x)=\left(f_{1}^{m}(x), f_{2}^{m}(x), \ldots, f_{n}^{m}(x)\right)^{T}$, is of order $2 m$.

Proof. Firstly, let us notice that the divided difference $[x+G(x), x-G(x) ; F]$ can be written as

$$
[x+G(x), x-G(x) ; F]=\frac{1}{2}([x+G(x), x ; F]+[x, x-G(x) ; F]) .
$$


By using (11), Taylor expansions of $[x+G(x), x ; F]$ and $[x, x-G(x) ; F]$ are, respectively,

$$
\begin{aligned}
{[x+G(x), x ; F]=} & F^{\prime}(\bar{x})\left[I+2 C_{2} e+3 C_{3} e^{2}+\ldots+m C_{m} e^{m-1}+\left(C_{2} A_{m}+(m+1) C_{m+1}\right) e^{m}\right. \\
& +\left(C_{2} A_{m+1}+C_{3} A_{m}+(m+2) C_{m+2}\right) e^{m+1}+\left(C_{2} A_{m+2}+C_{3} A_{m+1}+C_{4} A_{m}+(m+3) C_{m+3}\right) e^{m+2} \\
& +\cdots+\left(C_{2} A_{m+m-1}+C_{3} A_{m+m-2}+\cdots+C_{m-1} A_{m}+2 m C_{2 m}\right) e^{2 m-1} \\
& +\left(C_{2} A_{2 m}+\left(C_{3} A_{m}^{2}+A_{2 m-1}\right)+C_{4} A_{2 m-2}+(2 m+1) C_{2 m+1}\right) e^{2 m} \\
& +\left(C_{2} A_{2 m+1}+\left(C_{3} A_{m} A_{m+1}+C_{3} A_{m+1} A_{m}+C_{4} A_{m}^{2}\right)+\right. \\
& \left.\left.C_{4} A_{2 m-1}+C_{5} A_{2 m-2}+(2 m+2) C_{2 m+2}\right)\right) e^{2 m+1}+O\left(e^{2 m+2}\right)
\end{aligned}
$$

and

$$
\begin{aligned}
{[x, x-G(x) ; F]=} & F^{\prime}(\bar{x})\left[I+2 C_{2} e+3 C_{3} e^{2}+\ldots+m C_{m} e^{m-1}+\left(C_{2}\left(-A_{m}\right)+(m+1) C_{m+1}\right) e^{m}\right. \\
& +\left(C_{2}\left(-A_{m+1}\right)+C_{3}\left(-A_{m}\right)+(m+2) C_{m+2}\right) e^{m+1} \\
& +\left(C_{2}\left(-A_{m+2}\right)+C_{3}\left(-A_{m+1}\right)+C_{4}\left(-A_{m}\right)+(m+3) C_{m+3}\right) e^{m+2} \\
& +\cdots+\left(C_{2}\left(-A_{m+m-1}\right)+C_{3}\left(-A_{m+m-2}\right)+\cdots+C_{m-1}\left(-A_{m}\right)+2 m C_{2 m}\right) e^{2 m-1} \\
& +\left(\left(C_{2}\left(-A_{2 m}\right)+\left(C_{3}\left(-A_{m}\right)^{2}+\left(-A_{2 m-1}\right)\right)+C_{4}\left(-A_{2 m-2}\right)+(2 m+1) C_{2 m+1}\right) e^{2 m}\right. \\
& +\left(C_{2}\left(-A_{2 m+1}\right)+\left(C_{3}\left(-A_{m}\right)\left(-A_{m+1}\right)+C_{3}\left(-A_{m+1}\right)\left(-A_{m}\right)+C_{4}\left(-A_{m}\right)^{2}\right)\right. \\
& \left.\left.+C_{4}\left(-A_{2 m-1}\right)+C_{5}\left(-A_{2 m-2}\right)+(2 m+2) C_{2 m+2}\right)\right) e^{2 m+1}+O\left(e^{2 m+2}\right) .
\end{aligned}
$$

95 Let us remark that all the terms of order $m, m+1, \ldots, 2 m-1$ of $[x+G(x), x ; F]$ and $[x-G(x), x ; F]$, which contain $A_{m}, A_{m+1}, A_{m+2}, \ldots$ are opposite; so, the order of the central divided difference is $2 m$.

In the next section, we construct Jacobian-free iterative methods from known ones by replacing the Jacobian matrices in their respective iterative expressions by $m$ th-order non-symmetric divided differences. We show that the original order of convergence is preserved if the appropriate value of $m$ is employed.

\section{Applying divided differences on some iterative methods}

In the following, we use the divided differences introduced in the previous section on some known iterative methods of different orders of convergence. We show that, when a divided difference of suitable order is applied on the iterative methods as an approximation of the different Jacobian matrices involved, the obtained method preserves the order of convergence of the previous one. Theorem 2.1 and Corollary 2.1 give us a good tool for designing Jacobian-free iterative methods with desirable order. The following result shows that $m \geq 2$ in the definition of $G(x)$ is enough to preserve the order of the iterative method $\mathrm{NLM}_{8}$. Similar results can be obtained for any iterative method of arbitrary order of convergence.

Theorem 3.1. Let $F: D \subseteq \mathbb{R}^{n} \longrightarrow \mathbb{R}^{n}$ be sufficiently differentiable function at each point of an open neighborhood $D$ of $\bar{x} \in \mathbb{R}^{n}$, that is a solution of $F(x)=0$ and let us suppose the initial estimation $x^{(0)}$ is close enough to $\bar{x}$. Let us assume that $F^{\prime}(x)$ is continuous and nonsingular in $\bar{x}$. Then, sequence $\left\{x^{(k)}\right\}_{k \geq 0}$ obtained from iterative expression

$$
\begin{aligned}
y^{(k)} & =x^{(k)}-\left[x^{(k)}+G\left(x^{(k)}\right), x^{(k)} ; F\right]^{-1} F\left(x^{(k)}\right), \\
z^{(k)} & =y^{(k)}-\left[\frac{13}{4} I-H\left(x^{(k)}\right)\left(\frac{7}{2} I-\frac{5}{4} H\left(x^{(k)}\right)\right)\right]\left[x^{(k)}+G\left(x^{(k)}\right), x^{(k)} ; F\right]^{-1} F\left(y^{(k)}\right), \\
x^{(k+1)} & =z^{(k)}-\left[\frac{7}{2} I-H\left(x^{(k)}\right)\left(4 I-\frac{3}{2} H\left(x^{(k)}\right)\right)\right]\left[x^{(k)}+G\left(x^{(k)}\right), x^{(k)} ; F\right]^{-1} F\left(z^{(k)}\right),
\end{aligned}
$$

where $H\left(x^{(k)}\right)=\left[x^{(k)}+G\left(x^{(k)}\right), x^{(k)} ; F\right]^{-1}\left[y^{(k)}+G\left(y^{(k)}\right), y^{(k)} ; F\right]$ and $G(x)=\left(f_{1}^{m}(x), f_{2}^{m}(x), \ldots, f_{n}^{m}(x)\right)^{T}$, converges to $\bar{x}$ with order eight if $m \geq 2$. 
Proof. Let

$$
F\left(x^{(k)}\right)=F^{\prime}(\bar{x})\left[e^{(k)}+C_{2} e^{(k)^{2}}+C_{3}\left(e^{(k)}\right)^{3}+C_{4} e^{(k)^{4}}+C_{5} e^{(k)^{5}}+C_{6} e^{(k)^{6}}+C_{7} e^{(k)^{7}}\right]+O\left(e^{(k)^{8}}\right)
$$

110 be the Taylor expansion of $F\left(x^{(k)}\right)$ about $\bar{x}$, where $e^{(k)}=x^{(k)}-\bar{x}$ and $C_{k}=\frac{1}{k !}\left[F^{\prime}(\bar{x})\right]^{-1} F^{(k)}(\bar{x}), k \geq 2$. So the expansion of $F^{\prime}\left(x^{(k)}\right)$ is

$$
F^{\prime}\left(x^{(k)}\right)=F^{\prime}(\bar{x})\left[I+2 C_{2} e^{(k)}+3 C_{3} e^{(k)^{2}}+4 C_{4} e^{(k)^{3}}+5 C_{4} e^{(k)^{4}}+6 C_{5} e^{(k)^{5}}+7 C_{6} e^{(k)^{6}}\right]+O\left(e^{(k)^{7}}\right) .
$$

According to Theorem 2.1, $\left[x^{(k)}+G\left(x^{(k)}\right), x^{(k)} ; F\right]$ for $m=2$ is an approximation of order 2 of Jacobian matrix $F^{\prime}\left(x^{(k)}\right)$ and according to 11 its Taylor expansion is

$\left[x^{(k)}+G\left(x^{(k)}\right), x^{(k)} ; F\right]=F^{\prime}(\bar{x})\left[I+2 C_{2} e^{(k)}+\left(C_{2} A_{2}+3 C_{3}\right) e^{(k)^{2}}+\left(C_{2} A_{3}+3 C_{3} A_{2}+4 C_{4}\right) e^{(k)^{3}}\right]+O\left(e^{(k)^{4}}\right)$,

so, its inverse can be expanded as

$$
\left[x^{(k)}+G\left(x^{(k)}\right), x^{(k)} ; F\right]^{-1}=\left[I+X_{2} e^{(k)}+X_{3} e^{(k)^{2}}+X_{4} e^{(k)^{3}}\right]\left[F^{\prime}(\bar{x})\right]^{-1}+O\left(e^{(k)^{4}}\right),
$$

is also a second order approximation of $\left[F^{\prime}\left(x^{(k)}\right)\right]^{-1}$. The terms of this development are obtained from

$$
\left[x^{(k)}+G\left(x^{(k)}\right), x^{(k)} ; F\right]^{-1}\left[x^{(k)}+G\left(x^{(k)}\right), x^{(k)} ; F\right]=\left[x^{(k)}+G\left(x^{(k)}\right), x^{(k)} ; F\right]\left[x^{(k)}+G\left(x^{(k)}\right), x^{(k)} ; F\right]^{-1}=I .
$$

Then, we have

$$
\begin{aligned}
& X_{2}=-2 C_{2}, \\
& X_{3}=4 C_{2}^{2}-3 C_{3}-C_{2} A_{2}, \\
& X_{4}=-C_{2} A_{3}+\left(4 C_{2}^{2}-3 C_{3}\right) A_{2}-8 C_{2}^{3}+6 C_{2} C_{3}+6 C_{3} C_{2}-4 C_{4} .
\end{aligned}
$$

Now, by applying $(12)$, for the first step of $\mathrm{NLM}_{8}$ method we get

$$
\begin{aligned}
e_{y}^{(k)}= & \left(y^{(k)}-\bar{x}\right)=\left(x^{(k)}-\bar{x}\right)-\left[x^{(k)}+G\left(x^{(k)}\right), x^{(k)} ; F\right]^{-1} F\left(x^{(k)}\right) \\
= & C_{2} e^{(k)^{2}}+\left(C_{2} A_{2}+2 C_{3}-2 C_{2}^{2}\right) e^{(k)^{3}}+\left(C_{2} A_{3}-3\left(C_{2}^{2}-C_{3}\right) A_{2}\right. \\
& \left.+4 C_{2}^{3}-4 C_{2} C_{3}-3 C_{3} C_{2}+3 C_{4}\right) e^{(k)^{4}}+O\left(e^{(k)^{5}}\right) .
\end{aligned}
$$

115 Again, by using 111 for $\left[y^{(k)}+G\left(y^{(k)}\right), y^{(k)} ; F\right]$ as an approximation for $F^{\prime}\left(y^{(k)}\right)$ we have $\left[y^{(k)}+G\left(y^{(k)}\right), y^{(k)} ; F\right]=F^{\prime}(\bar{x})\left[I+2 C_{2} e_{y}^{(k)}+\left(C_{2} A_{2}+3 C_{3}\right)\left(e_{y}^{(k)}\right)^{2}+\left(C_{2} A_{3}+3 C_{3} A_{2}+4 C_{4}\right)\left(e_{y}^{(k)}\right)^{3}\right]+O\left(\left(e_{y}^{(k)}\right)^{4}\right)$,

where $e_{y}^{(k)}=y^{(k)}-\bar{x}$. From 12 and 13 we get

$$
\begin{aligned}
H\left(x^{(k)}\right)= & {\left[x^{(k)}+G\left(x^{(k)}\right), x^{(k)} ; F\right]^{-1}\left[y^{(k)}+G\left(y^{(k)}\right), y^{(k)} ; F\right] } \\
= & I-2 C_{2} e^{(k)}+2 C_{2} e_{y}^{(k)}+\left(4 C_{2}^{2}-3 C_{3}-C_{2} A_{2}\right) e^{(k)^{2}}-4 C_{2} e^{(k)} C_{2} e_{y}^{(k)} \\
& +\left(-C_{2} A_{3}+\left(4 C_{2}^{2}-3 C_{3}\right) A_{2}-8 C_{2}^{3}+6 C_{2} C_{3}+6 C_{3} C_{2}-4 C_{4}\right) e^{(k)^{3}}+O\left(e^{(k)^{4}}\right) .
\end{aligned}
$$

So, by substituting (12) and (14) into the second step of the method, its error can be written as

$$
\begin{aligned}
e_{z}^{(k)} & =\left(z^{(k)}-\bar{x}\right)=\left(y^{(k)}-\bar{x}\right)-\left[\frac{13}{4} I+H\left(x^{(k)}\right)\left(-\frac{7}{2} I+\frac{5}{4} H^{(k)}\right)\right]\left[x^{(k)}+G\left(x^{(k)}\right), x^{(k)} ; F\right]^{-1} F\left(y^{(k)}\right) \\
& =\frac{1}{2}\left(28 C_{2}^{3}+C_{2} C_{3}-3 C_{3} C_{2}\right) C_{2} e^{(k)^{5}}+O\left(e^{(k)^{6}}\right) .
\end{aligned}
$$

Now, Taylor development of $F\left(z^{(k)}\right)$ about $\bar{x}$ yields

$$
F\left(z^{(k)}\right)=F^{\prime}(\bar{x})\left[e_{z}^{(k)}+O\left(\left(e_{z}^{(k)}\right)^{2}\right)\right],
$$


where $e_{z}^{(k)}=z^{(k)}-\bar{x}$. Finally, by using $12,, 14,15$ and 16 for the third step we have

$$
\begin{aligned}
e^{(k+1)}= & \left(z^{(k)}-\bar{x}\right)-\left[\frac{7}{2} I-H\left(x^{(k)}\right)\left(4 I-\frac{3}{2} H\left(x^{(k)}\right)\right)\right]\left[x^{(k)}+G\left(x^{(k)}\right), x^{(k)} ; F\right]^{-1} F\left(z^{(k)}\right) \\
= & \frac{1}{2}\left[560 C_{2}^{6}+28 C_{2} C_{3} C_{2}^{3}+20 C_{2}^{4} C_{3}-84 C_{3} C_{2}^{4}-60 C_{2}^{3} C_{3} C_{2}+C_{2} C_{3} C_{2} C_{3}\right. \\
& \left.-3 C_{2} C_{3}^{2} C_{2}-3 C_{3} C_{2}^{2} C_{3}+9 C_{3} C_{2} C_{3} C_{2}\right] C_{2} e^{(k)^{8}}+O\left(e^{(k)^{9}}\right),
\end{aligned}
$$

120 and this completes the proof.

In a similar way as in Theorem 3.1, we have the following result.

Corollary 3.1. Under the same assumptions as in Theorem 3.1, the iterative schemes obtained by replacing in the following methods the Jacobian matrices by divided differences with suitable values of parameter $m$, hold the original order of convergence.

1) The Jacobian-free iterative methods obtained from Ostrowski 3 and $M_{4,3}$ preserve the original fourthorder of convergence for $m \geq 2$.

2) The Jacobian-free iterative methods obtained from Jarratt 4 . Montazeri 1 and $M 1_{4}$ preserve the original fourth-order of convergence for $m \geq 3$.

3) The Jacobian-free iterative method $M_{6,3}$ preserves the original sixth-order of convergence for $m \geq 2$.

4) Finally, the Jacobian-free iterative methods, CCGT1 and CCGT2 preserve the original eighth-order of convergence for $m \geq 2$.

Proof: By using Taylor expansion around $\bar{x}$ of the different expressions of the iterative formulas, the following error equations are obtained.

1) The error equation of modified Ostrowski's method for $m=2$ is equal to

$$
E=\left(C_{2}^{3}-C_{2} A_{2} C_{2}-C_{2} C_{3}\right) e^{(k)^{4}}+O\left(e^{(k)^{5}}\right)=E_{O}-\left(C_{2} A_{2} C_{2}\right) e^{(k)^{4}}+O\left(e^{(k)^{5}}\right),
$$

where $E_{O}$ is the error equation of the original Ostrowski's method 3 .

On the other hand, the error equation of Jacobian-free $\mathrm{M}_{4,3}$ method for $m=2$ is equal to

$$
\begin{aligned}
E & =\left(5 C_{2}^{3}+2 C_{2}^{2} A_{2}-3 C_{2} A_{2} C_{2}-C_{3} C_{2}\right) e^{(k)^{4}}+O\left(e^{(k)^{5}}\right) \\
& =E_{M_{4,3}}+\left(2 C_{2}^{2} A_{2}-3 C_{2} A_{2} C_{2}\right) e^{(k)^{4}}+O\left(e^{(k)^{5}}\right),
\end{aligned}
$$

where $E_{M_{4,3}}$ is the error of the original $\mathrm{M}_{4,3}$ scheme.

2) The error of modified Jarratt's method for $m=3$ is equal to

$$
\begin{aligned}
E & =\left[C_{2}^{3}+\frac{1}{36} F^{\prime}(\bar{x})^{3} C_{2}+\frac{1}{4} C_{2} A_{3}-C_{2} C_{3}+\frac{1}{9} C_{4}\right] e^{(k)^{4}}+O\left(e^{(k)^{5}}\right) \\
& =E_{J}+\left[\frac{1}{36} F^{\prime}(\bar{x})^{3} C_{2}+\frac{1}{4} C_{2} A_{3}\right] e^{(k)^{4}}+O\left(e^{(k)^{5}}\right)
\end{aligned}
$$

where $E_{J}$ is the error of the original Jarratt's procedure.

Also, the error of modified Montazeri's scheme for $m=3$ is

$$
\begin{aligned}
E & =\left[5 C_{2}^{3}+\frac{1}{36} F^{\prime}(\bar{x})^{3} C_{2}+\frac{1}{4} C_{2} A_{3}-C_{2} C_{3}+\frac{1}{9} C_{4}\right] e^{(k)^{4}}+O\left(e^{(k)^{5}}\right) \\
& =E_{S}+\left[\frac{1}{36} F^{\prime}(\bar{x})^{3} C_{2}+\frac{1}{4} C_{2} A_{3}\right] e^{(k)^{4}}+O\left(e^{(k)^{5}}\right),
\end{aligned}
$$


being $E_{S}$ the error of the original method.

The error for the Jacobian-free fourth order method $\mathrm{M}_{4}$ for $m=3$ is

$$
\begin{aligned}
E & \left.=\left[\frac{8}{3} C_{2}^{3}+\frac{1}{36} F^{\prime}(\bar{x})^{3} C_{2}+\frac{1}{4} C_{2} A_{3}-C_{2} C_{3}+\frac{1}{9} C_{4}\right] e^{(k)^{4}}+O e^{(k)^{5}}\right) \\
& =E_{M 1_{4}}+\left[\frac{1}{36} F^{\prime}(\bar{x})^{3} C_{2}+\frac{1}{4} C_{2} A_{3}\right] e^{(k)^{4}}+O\left(e^{(k)^{5}}\right),
\end{aligned}
$$

where $E_{M l_{4}}$ is the error of the original method.

3) The error for modified sixth order method $\mathrm{M}_{6,3}$ for $m=3$ is equal to

$$
\begin{aligned}
E= & \left(-6 C_{2}^{2} C_{3} C_{2}-5 C_{3} C_{2}^{3}+C_{3}^{2} C_{2}+30 C_{2}^{5}+C_{2}^{2} A_{2} C_{2} A_{2}+2 C_{2}^{2} A_{2} C_{3}-6 C_{2} A_{2} C_{3} C_{2}\right. \\
& \left.-5 C_{2} A_{2} C_{2} C_{3}\right) e^{(k)^{6}}+O\left(e^{(k)^{7}}\right) \\
= & E_{M_{4,3}}+\left(C_{2}^{2} A_{2} C_{2} A_{2}+2 C_{2}^{2} A_{2} C_{3}-6 C_{2} A_{2} C_{3} C_{2}-5 C_{2} A_{2} C_{2} C_{3}\right) e^{(k)^{6}}+O\left(e^{(k)^{7}}\right)
\end{aligned}
$$

145 being $E_{M_{6,3}}$ is the error of the original scheme.

4) The error for Jacobian-free eight order methods CCGT1 and CCGT2 for $m=2$ are respectively

$$
E=\left(C_{2} C_{3}-3 C_{3} C_{2}\right)\left(\frac{1}{2} C_{2} C_{3} C_{2}-\frac{3}{2} C_{3} C_{2}^{2}\right) e^{(k)^{8}}+O\left(e^{(k)^{9}}\right)=E_{C C G T 1},
$$

and

$$
E=\left(4 C_{2}^{3}+C_{2} C_{3}-3 C_{3} C_{2}\right)\left(2 C_{2}^{4}-\frac{3}{2} C_{3} C_{2}^{2}+\frac{1}{2} C_{2} C_{3} C_{2}\right) e^{(k)^{8}}+O\left(e^{(k)^{9}}\right)=E_{C C G T 2},
$$

where $E_{C C G T 1}$ and $E_{C C G T 2}$ are respectively the error of the original CCGT1 and CCGT2 methods.

From Corollary 3.1, it can be conjectured that if appropriate $m$-powers are used in the divided differences that replace the Jacobian matrices in an iterative method, the order of convergence of the resulting iterative scheme is preserved respect to the original one.

Moreover, let us notice the relation between the order of first step of above iterative methods and the value of parameter $m$ (the order of divided difference) that is needed to hold the order of convergence. In Ostrowski's and $\mathrm{NLM}_{4,3}$ schemes, the order of convergence is preserved with $m=2$, because the first step

155 already has order 2 and it is held with the divided difference. In Jarratt', Montazeri's and $\mathrm{M}_{4}$, with $m=2$ and linear convergence at the first step, we need $m=3$. This is the main difference between this conjecture and the scalar-case conjecture presented in 24 .

Let us also note that we use forward divided differences in Theorem 3.1 and Corollary 3.1, but in general case, any divided difference with the same or higher order can be used. For example, if we use central divided 160 difference, all the results in the Theorem 3.1 and Corollary 3.1 are satisfied with $\frac{m}{2}$, when $m$ is even and with $\left\lfloor\frac{m}{2}\right\rfloor+1$ when $m$ is odd, but in these cases the computational effort of computing symmetric divided differences is higher than non-symmetric ones.

\section{Numerical results}

In this section, we numerically estimate the Jacobian matrices involved in some iterative methods of different orders of convergence, by using the proposed technique. These experiments show that by using suitable values of $m$ in the divided differences, the order of convergence of all iterative methods are preserved. By using the approximated computational order of convergence (ACOC) introduced in [26] as

$$
p \approx A C O C=\frac{\ln \left(\left\|x^{(k+1)}-x^{(k)}\right\| /\left\|x^{(k)}-x^{(k-1)}\right\|\right)}{\ln \left(\left\|x^{(k)}-x^{(k-1)}\right\| /\left\|x^{(k-1)}-x^{(k-2)}\right\|\right)},
$$

we check the theoretical order of convergence $p$ for the resulting Jacobian-free methods. 
All the experiments have been carried out in Matlab 2017 with variable precision arithmetics and the stopping criteria are $\left\|F\left(x^{(k+1)}\right)\right\|<10^{-200}$ and $\left\|x^{(k+1)}-x^{(k)}\right\|<10^{-200}$; the iterations terminated when both criteria are satisfied. Moreover, the computational time $(T)$ in seconds is calculated by taking the mean of 10 performances of the program for each method. These calculations have been made with an Intel Core processor i7-4700HQ with a CPU of $2.40 \mathrm{GHz}$ and $8.0 \mathrm{~GB}$ of RAM memory.

Example 1. Let us consider the following nonlinear system

$$
x_{i}-\cos \left(2 x_{i}-\sum_{j=1}^{4} x_{j}\right)=0, \quad i=1,2, \ldots, n .
$$

The solution of this problem is $\bar{x}=(0.5149,0.5149, \ldots, 0.5149)^{T}$. We use $n=20$, initial guess $x^{(0)}=$ $175(1,1, \ldots, 1)^{T}$ and divided differences $\left[x^{(k)}+G(x), x^{(k)} ; F\right]$ with $m=1,2,3,4$ (these four divided difference are respectively denoted by D1, D2, D3 and D4), central divided difference $\left[x^{(k)}+G(x), x^{(k)}-G(x) ; F\right]$ with $m=1$ (which is denoted by D5) and with $m=2$ (which is denoted by D6) for Ostrowski', Jarratt', Montazeri's, $\mathrm{M1}_{4}, \mathrm{M}_{4,3}, \mathrm{M}_{6,3}$, CCGT1 and CCGT2 methods.

We list the numerical results for this problem in Table 1. It shows the coincidence of numerical results with theoretical ones that were proved in Theorem 3.1 and Corollary 3.2. In this table, we can see that the fourth-order iterative methods Ostrowski and $\mathrm{M}_{4,3}$ preserve the order of convergence for $m \geq 2$ when forward divided difference is applied and for $m \geq 1$ when central divided difference is used. The fourth order iterative methods, Jarratt, Montazeri and $\mathrm{M}_{4}$ hold the fourth-order if $m \geq 3$ when divided difference is non-symmetric and if $m \geq 2$ when we use central divided differences. Also, eighth-order iterative methods, CCGT1 and CCGT2 preserve the order of convergence for $m \geq 2$ in case of non-symmetric divided differences and for $m \geq 1$ when central divided differences are used.

Example 2. Consider the following nonlinear system

$$
\begin{aligned}
x_{i}^{2} x_{i+1}-1 & =0, \quad i=1,2, \ldots, n-1, \\
x_{n}^{2} x_{1}-1 & =0 .
\end{aligned}
$$

The solution of this problem is $\bar{x}=(1,1, \ldots, 1)^{T}$. We use $n=9$ and the initial guess $x^{(0)}=(1.25,1.25, \ldots, 1.25)^{T}$. We list numerical results of this problem in Table 2. In this example also the stopping criteria $\left\|F\left(x^{(k+1)}\right)\right\|<$ $10^{-200}$ and $\left\|x^{(k+1)}-x^{(k)}\right\|<10^{-200}$ are used and the iterations finish when both criteria are satisfied. Similar results to Example 1 for Ostrowski', Jarratt', Montazeri's, M14, $\mathrm{M}_{4,3}, \mathrm{M}_{6,3}, \mathrm{CCGT1}$ and CCGT2 methods have been obtained, except in case of Ostrowski's scheme, that now only converges with symmetric divided differences.

\section{Conclusions}

In this paper, a new technique to transform iterative schemes for solving nonlinear systems into Jacobianfree ones is designed, preserving the order of convergence in all cases. The key fact of this new approach is the $m$-th power of the coordinate functions of $F(x)$, that needs different values depending on the order of the first step of the method. This general procedure has been checked, both theoretical and numerically, showing the preservation of the order of convergence and very precise results when the appropriate values of $m$ are employed.

Acknowledgement: The authors would like to thank the anonymous reviewers for their comments and suggestions that have improved the final version of this manuscript.

[1] F. Awawdeh, On new iterative method for solving systems of nonlinear equations, Numer. Algor. 54 (2010) 395-409.

[2] A. Cordero, J.L. Hueso, E. Martínez, J.R. Torregrosa, A modified Newton-Jarratt's composition, Numer. Algor. 55 (2010) 87-99. 


\begin{tabular}{|c|c|c|c|c|c|c|c|}
\hline Method & & D1 & D2 & D3 & D4 & D5 & D6 \\
\hline \multirow{5}{*}{ Ostrowski } & $\mathrm{ACOC}$ & 3.0000 & 4.0000 & 4.0000 & 4.0000 & 4.0000 & 4.0000 \\
\hline & & 7 & 6 & & & 6 & 6 \\
\hline & $\left\|x^{(k+1)}-x^{(k)}\right\|$ & $1.0556 \mathrm{e}-522$ & $6.434 \mathrm{e}-796$ & $1.3326 \mathrm{e}-273$ & $1.3313 \mathrm{e}-248$ & $6.9935 \mathrm{e}-521$ & $5.512 \mathrm{e}-774$ \\
\hline & $\left\|F\left(x^{(k+1)}\right)\right\|$ & $2.3171 \mathrm{e}-1567$ & $4.4011 \mathrm{e}-3183$ & $2.0519 \mathrm{e}-1094$ & $2.0438 \mathrm{e}-994$ & $1.0102 \mathrm{e}-2082$ & $6.0053 \mathrm{e}-3096$ \\
\hline & $T(s)$ & 24.7808 & 20.7786 & 17.4160 & 17.3520 & 20.6182 & 20.6350 \\
\hline \multirow{5}{*}{ Jarratt } & $\mathrm{ACOC}$ & 2.0000 & 3.0000 & 4.0000 & 4.0000 & 3.0000 & 4.0000 \\
\hline & iter & 9 & 6 & 6 & 5 & 7 & 6 \\
\hline & $\left\|x^{(k+1)}-x^{(k)}\right\|$ & $1.8967 \mathrm{e}-298$ & $7.36 \mathrm{e}-203$ & $6.6505 \mathrm{e}-716$ & $9.802 \mathrm{e}-239$ & $1.4213 \mathrm{e}-416$ & $3.1146 \mathrm{e}-609$ \\
\hline & $\left\|F\left(x^{(k+1)}\right)\right\|$ & $1.1244 \mathrm{e}-596$ & $5.0423 \mathrm{e}-608$ & $1.3704 \mathrm{e}-2862$ & $5.6118 \mathrm{e}-955$ & $4.0302 \mathrm{e}-1249$ & $5.7205 \mathrm{e}-2437$ \\
\hline & $T(s)$ & 30.9306 & 20.6839 & 20.4614 & 17.5762 & 24.4436 & 20.7386 \\
\hline \multirow{5}{*}{ Montazeri } & $\mathrm{ACOC}$ & 2.0000 & 3.0000 & 4.0000 & 4.0000 & 3.0000 & 4.0000 \\
\hline & iter & 9 & 6 & 6 & 5 & 7 & 6 \\
\hline & $\left\|x^{(k+1)}-x^{(k)}\right\|$ & $8.0421 \mathrm{e}-290$ & $1.0054 \mathrm{e}-202$ & $1.0812 \mathrm{e}-712$ & $1.6694 \mathrm{e}-233$ & $3.1573 \mathrm{e}-410$ & $1.9742 \mathrm{e}-580$ \\
\hline & $\left\|F\left(x^{(k+1)}\right)\right\|$ & $2.0214 \mathrm{e}-579$ & $1.2853 \mathrm{e}-607$ & $1.0478 \mathrm{e}-2849$ & $9.8714 \mathrm{e}-934$ & $4.4176 \mathrm{e}-1230$ & $1.9305 \mathrm{e}-2321$ \\
\hline & $T(s)$ & 31.9957 & 21.4287 & 21.1808 & 18.3136 & 25.5962 & 20.8158 \\
\hline \multirow{5}{*}{$\mathrm{M}_{4}$} & $\mathrm{ACOC}$ & 2.0000 & 3.0000 & 4.0000 & 4.0000 & 3.0000 & 4.0000 \\
\hline & & & & 6 & & & 6 \\
\hline & $\left\|x^{(k+1)}-x^{(k)}\right\|$ & $7.8556 \mathrm{e}-296$ & $8.1396 \mathrm{e}-203$ & $8.4371 \mathrm{e}-715$ & $2.0844 \mathrm{e}-236$ & $1.1085 \mathrm{e}-414$ & $1.4123 \mathrm{e}-595$ \\
\hline & $\left\|F\left(x^{(k+1)}\right)\right\|$ & $1.9288 \mathrm{e}-591$ & $6.8204 \mathrm{e}-608$ & $3.6617 \mathrm{e}-2858$ & $1.5647 \mathrm{e}-945$ & $1.9118 \mathrm{e}-1243$ & $3.2981 \mathrm{e}-2382$ \\
\hline & $T(s)$ & 37.2992 & 24.6983 & 24.3969 & 20.3472 & 28.6396 & 24.1269 \\
\hline \multirow{5}{*}{$\mathrm{M}_{4,3}$} & $\mathrm{ACOC}$ & 3.0000 & 4.0000 & 4.0000 & 4.0000 & 4.0000 & 4.0000 \\
\hline & iter & & & & & & \\
\hline & $\left\|x^{(k+1)}-x^{(k)}\right\|$ & $1.0978 \mathrm{e}-485$ & $1.5927 \mathrm{e}-801$ & $4.1405 \mathrm{e}-267$ & $1.4506 \mathrm{e}-240$ & $1.1359 \mathrm{e}-466$ & $8.0945 \mathrm{e}-737$ \\
\hline & $\left\|F\left(x^{(k+1)}\right)\right\|$ & $2.6059 \mathrm{e}-1456$ & $1.2259 \mathrm{e}-3205$ & $3.8606 \mathrm{e}-1068$ & $5.8154 \mathrm{e}-962$ & $8.1349 \mathrm{e}-1866$ & $5.639 \mathrm{e}-2947$ \\
\hline & $T(s)$ & 23.5693 & 20.5748 & 17.0164 & 17.0648 & 19.3329 & 19.5433 \\
\hline \multirow{5}{*}{$\mathrm{M}_{6,3}$} & $\mathrm{ACOC}$ & 4.0000 & 6.0000 & 6.0000 & 6.0000 & 6.0000 & 6.0000 \\
\hline & iter & & & & & & 5 \\
\hline & $\left\|x^{(k+1)}-x^{(k)}\right\|$ & $2.3177 \mathrm{e}-690$ & $3.111 \mathrm{e}-884$ & $1.2841 \mathrm{e}-1158$ & $2.3186 \mathrm{e}-1097$ & $7.1803 \mathrm{e}-497$ & $9.7547 \mathrm{e}-808$ \\
\hline & $\left\|F\left(x^{(k+1)}\right)\right\|$ & $1.309 \mathrm{e}-2760$ & $1.3047 \mathrm{e}-5304$ & $3.783 \mathrm{e}-6951$ & $1.3109 \mathrm{e}-6583$ & $1.4689 \mathrm{e}-2979$ & $7.2695 \mathrm{e}-4846$ \\
\hline & $T(s)$ & 22.3429 & 18.5369 & 18.4719 & 18.4323 & 18.5955 & 19.0419 \\
\hline \multirow{5}{*}{$\mathrm{NLM}_{8}$} & $\mathrm{ACOC}$ & 6.0000 & 8.0000 & 8.0000 & 8.0000 & 8.0000 & 8.0000 \\
\hline & iter & 5 & 4 & 4 & 4 & 4 & \\
\hline & $\left\|x^{(k+1)}-x^{(k)}\right\|$ & $2.1596 \mathrm{e}-810$ & $3.5541 \mathrm{e}-429$ & $5.181 \mathrm{e}-644$ & $3.2962 \mathrm{e}-503$ & $2.4708 \mathrm{e}-276$ & $2.5985 \mathrm{e}-602$ \\
\hline & $\left\|F\left(x^{(k+1)}\right)\right\|$ & $2.3699 \mathrm{e}-4861$ & $9.563 \mathrm{e}-3433$ & $1.9502 \mathrm{e}-5151$ & $5.2342 \mathrm{e}-4025$ & $5.2172 \mathrm{e}-2210$ & $7.8071 \mathrm{e}-4818$ \\
\hline & $T(s)$ & 34.8867 & 28.0154 & 30.6090 & 32.7031 & 29.0760 & 28.6488 \\
\hline \multirow{5}{*}{ CCGT1 } & $\mathrm{ACOC}$ & 6.0000 & 8.0000 & 8.0000 & 8.0000 & 8.0001 & 8.0000 \\
\hline & iter & 5 & 4 & 4 & 4 & 4 & 4 \\
\hline & $\left\|x^{(k+1)}-x^{(k)}\right\|$ & $2.4863 \mathrm{e}-810$ & $4.4171 \mathrm{e}-441$ & $3.1812 \mathrm{e}-584$ & $3.5715 \mathrm{e}-585$ & $4.1596 \mathrm{e}-290$ & $2.2693 \mathrm{e}-401$ \\
\hline & $\left\|F\left(x^{(k+1)}\right)\right\|$ & $5.5194 \mathrm{e}-4861$ & $2.129 \mathrm{e}-3529$ & $1.5412 \mathrm{e}-4674$ & $3.8893 \mathrm{e}-4682$ & $1.3167 \mathrm{e}-2321$ & $1.0332 \mathrm{e}-3211$ \\
\hline & $T(s)$ & 38.9875 & 31.0323 & 30.7696 & 30.4730 & 31.1474 & 30.4134 \\
\hline \multirow{5}{*}{ CCGT2 } & $\mathrm{ACOC}$ & 6.0000 & 8.0000 & 8.0000 & 8.0000 & 8.0000 & 8.0000 \\
\hline & iter & 5 & 4 & 4 & 4 & 4 & 4 \\
\hline & $\left\|x^{(k+1)}-x^{(k)}\right\|$ & $2.4242 \mathrm{e}-810$ & $3.851 \mathrm{e}-437$ & $6.6644 \mathrm{e}-588$ & $1.2459 \mathrm{e}-559$ & $7.25 \mathrm{e}-286$ & $2.6366 \mathrm{e}-397$ \\
\hline & $\left\|F\left(x^{(k+1)}\right)\right\|$ & $4.7416 \mathrm{e}-4861$ & $2.0147 \mathrm{e}-3497$ & $1.6209 \mathrm{e}-4703$ & $2.4177 \mathrm{e}-4477$ & $3.1795 \mathrm{e}-2287$ & $9.7269 \mathrm{e}-3179$ \\
\hline & $T(s)$ & 20.3045 & 16.2168 & 16.8689 & 16.2802 & 16.3636 & 18.0748 \\
\hline
\end{tabular}

Table 1: Numerical results for Example 1 


\begin{tabular}{|c|c|c|c|c|c|c|c|}
\hline Method & & D1 & D2 & D3 & D4 & D5 & D6 \\
\hline \multirow{5}{*}{ Ostrowski } & $\mathrm{ACOC}$ & - & - & - & - & 4.0000 & 4.0000 \\
\hline & & - & - & - & - & & 6 \\
\hline & $\left\|x^{(k+1)}-x^{(k)}\right\|$ & - & - & - & - & $1.3441 \mathrm{e}-398$ & $3.3016 \mathrm{e}-461$ \\
\hline & $\left\|F\left(x^{(k+1)}\right)\right\|$ & - & - & - & - & $8.462 \mathrm{e}-1593$ & $8.8018 \mathrm{e}-1844$ \\
\hline & $T(s)$ & - & - & - & - & 5.0964 & 5.2681 \\
\hline \multirow{5}{*}{ Jarratt } & $\mathrm{ACOC}$ & 2.0000 & 3.0000 & 4.0000 & 4.0000 & 3.0000 & 4.0000 \\
\hline & iter & 11 & 8 & 6 & 6 & 7 & 6 \\
\hline & $\left\|x^{(k+1)}-x^{(k)}\right\|$ & $5.2343 \mathrm{e}-368$ & $8.0284 \mathrm{e}-599$ & $2.0748 \mathrm{e}-251$ & $1.5966 \mathrm{e}-415$ & $7.7224 \mathrm{e}-401$ & $3.5737 \mathrm{e}-458$ \\
\hline & $\left\|F\left(x^{(k+1)}\right)\right\|$ & $4.1096 \mathrm{e}-735$ & $5.1747 \mathrm{e}-1795$ & $1.6816 \mathrm{e}-1003$ & $4.8132 \mathrm{e}-1661$ & $1.5351 \mathrm{e}-1201$ & $1.2082 \mathrm{e}-1831$ \\
\hline & $T(s)$ & 9.5910 & 6.9994 & 5.2894 & 5.3013 & 6.1825 & 5.2895 \\
\hline \multirow{5}{*}{ Montazeri } & $\mathrm{ACOC}$ & 2.0000 & 3.0000 & 4.0000 & 4.0000 & 3.0000 & 4.0000 \\
\hline & iter & 11 & 8 & 7 & 6 & & 6 \\
\hline & $\left\|x^{(k+1)}-x^{(k)}\right\|$ & $5.656 \mathrm{e}-351$ & $4.9847 \mathrm{e}-514$ & $7.018 \mathrm{e}-717$ & $1.8639 \mathrm{e}-228$ & $1.7672 \mathrm{e}-359$ & $1.1391 \mathrm{e}-365$ \\
\hline & $\left\|F\left(x^{(k+1)}\right)\right\|$ & $4.7986 \mathrm{e}-701$ & $1.2386 \mathrm{e}-1540$ & $3.2794 \mathrm{e}-2865$ & $6.2586 \mathrm{e}-912$ & $1.8395 \mathrm{e}-1077$ & $8.7289 \mathrm{e}-1461$ \\
\hline & $T(s)$ & 10.0803 & 7.3430 & 6.6295 & 5.8841 & 6.4126 & 5.5373 \\
\hline \multirow{5}{*}{$\mathrm{M}_{4}$} & $\mathrm{ACOC}$ & 2.0000 & 3.0000 & 4.0000 & 4.0000 & 3.0000 & 4.0000 \\
\hline & & 11 & 8 & 6 & & & \\
\hline & $\left\|x^{(k+1)}-x^{(k)}\right\|$ & $1.1821 \mathrm{e}-360$ & $6.0568 \mathrm{e}-557$ & $1.4753 \mathrm{e}-209$ & $1.5747 \mathrm{e}-287$ & $5.5116 \mathrm{e}-381$ & $1.1004 \mathrm{e}-433$ \\
\hline & $\left\|F\left(x^{(k+1)}\right)\right\|$ & $2.0961 \mathrm{e}-720$ & $2.222 \mathrm{e}-1669$ & $5.0006 \mathrm{e}-836$ & $1.3666 \mathrm{e}-1148$ & $5.5808 \mathrm{e}-1142$ & $3.258 \mathrm{e}-1733$ \\
\hline & $T(s)$ & 11.0443 & 7.8800 & 6.1416 & 5.9678 & 6.9497 & 6.5187 \\
\hline \multirow{5}{*}{$\mathrm{M}_{4,3}$} & $\mathrm{ACOC}$ & 3.0000 & 4.0000 & 4.0000 & 4.0000 & 4.0000 & 4.0000 \\
\hline & iter & & & & & & \\
\hline & $\left\|x^{(k+1)}-x^{(k)}\right\|$ & $2.5134 \mathrm{e}-254$ & $8.2802 \mathrm{e}-337$ & $1.1479 \mathrm{e}-347$ & $7.127 \mathrm{e}-351$ & $3.1622 \mathrm{e}-512$ & $6.746 \mathrm{e}-480$ \\
\hline & $\left\|F\left(x^{(k+1)}\right)\right\|$ & $6.3511 \mathrm{e}-761$ & $2.2633 \mathrm{e}-1345$ & $9.0031 \mathrm{e}-1389$ & $1.3378 \mathrm{e}-1401$ & $1.8517 \mathrm{e}-2047$ & $1.0739 \mathrm{e}-1917$ \\
\hline & $T(s)$ & 6.1787 & 5.4226 & 5.3997 & 5.4180 & 4.9456 & 5.0737 \\
\hline \multirow{5}{*}{$\mathrm{M}_{6,3}$} & $\mathrm{ACOC}$ & 4.0000 & 6.0000 & 6.0000 & 6.0000 & 6.0000 & 6.0000 \\
\hline & iter & & & & & & \\
\hline & $\left\|x^{(k+1)}-x^{(k)}\right\|$ & $1.1353 \mathrm{e}-391$ & $6.349 \mathrm{e}-395$ & $2.3965 \mathrm{e}-393$ & $3.8747 \mathrm{e}-401$ & $3.8633 \mathrm{e}-589$ & $1.7044 \mathrm{e}-560$ \\
\hline & $\left\|F\left(x^{(k+1)}\right)\right\|$ & $6.6456 \mathrm{e}-1564$ & $1.168 \mathrm{e}-2366$ & $6.1844 \mathrm{e}-2357$ & $1.1047 \mathrm{e}-2403$ & $1.8241 \mathrm{e}-3532$ & $8.0021 \mathrm{e}-3360$ \\
\hline & $T(s)$ & 5.7468 & 4.8483 & 4.9717 & 4.8520 & 4.7767 & 4.8018 \\
\hline \multirow{5}{*}{$\mathrm{NLM}_{8}$} & $\mathrm{ACOC}$ & 6.0000 & 8.0000 & 8.0000 & 8.0000 & 8.0000 & 8.0000 \\
\hline & iter & & & & & & 4 \\
\hline & $\left\|x^{(k+1)}-x^{(k)}\right\|$ & $1.172 \mathrm{e}-213$ & $2.2812 \mathrm{e}-710$ & $1.0217 \mathrm{e}-801$ & $7.2979 \mathrm{e}-854$ & $7.0254 \mathrm{e}-1283$ & $8.4744 \mathrm{e}-211$ \\
\hline & $\left\|F\left(x^{(k+1)}\right)\right\|$ & $9.3593 \mathrm{e}-1278$ & $2.6583 \mathrm{e}-5678$ & $4.303 \mathrm{e}-6409$ & $2.9161 \mathrm{e}-6826$ & $2.151 \mathrm{e}-10258$ & $9.6411 \mathrm{e}-1682$ \\
\hline & $T(s)$ & 8.805712 & 8.9025 & 9.1058 & 9.5024 & 9.3471 & 9.6289 \\
\hline \multirow{5}{*}{ CCGT1 } & $\mathrm{ACOC}$ & 6.0000 & 8.0000 & 8.0000 & 8.0000 & 8.0000 & 8.0000 \\
\hline & iter & & & 4 & & & 4 \\
\hline & $\left\|x^{(k+1)}-x^{(k)}\right\|$ & $2.164 \mathrm{e}-257$ & $3.9021 \mathrm{e}-1339$ & $3.6681 \mathrm{e}-269$ & $3.8264 \mathrm{e}-1410$ & $6.9258 \mathrm{e}-301$ & $3.5186 \mathrm{e}-353$ \\
\hline & $\left\|F\left(x^{(k+1)}\right)\right\|$ & $3.708 \mathrm{e}-1540$ & $1.6385 \mathrm{e}-10711$ & $9.9916 \mathrm{e}-2152$ & $1.55 \mathrm{e}-8458$ & $1.6136 \mathrm{e}-2405$ & $7.1616 \mathrm{e}-2824$ \\
\hline & $T(s)$ & 8.6980 & 8.0312 & 6.3344 & 7.9075 & 6.8772 & 6.7768 \\
\hline \multirow{5}{*}{ CCGT2 } & $\mathrm{ACOC}$ & 6.0000 & 8.0000 & 8.0000 & 8.0000 & 8.0000 & 8.0000 \\
\hline & iter & 5 & 5 & 5 & 4 & 4 & 4 \\
\hline & $\left\|x^{(k+1)}-x^{(k)}\right\|$ & $2.094 \mathrm{e}-244$ & $1.2852 \mathrm{e}-1043$ & $2.4221 \mathrm{e}-1394$ & $1.3845 \mathrm{e}-229$ & $1.5801 \mathrm{e}-226$ & $5.4932 \mathrm{e}-258$ \\
\hline & $\left\|F\left(x^{(k+1)}\right)\right\|$ & $3.0446 \mathrm{e}-1462$ & $5.6736 \mathrm{e}-8346$ & $9.9717 \mathrm{e}-8364$ & $1.0286 \mathrm{e}-1833$ & $2.9612 \mathrm{e}-1809$ & $6.3184 \mathrm{e}-2061$ \\
\hline & $T(s)$ & 5.1881 & 5.2219 & 5.2360 & 4.0400 & 4.1747 & 4.0705 \\
\hline
\end{tabular}

Table 2: Numerical results for Example 2 
[3] C. Grosan, A. Abraham, A new approach for solving nonlinear equations systems, IEEE Trans. Syst. Man Cybernet Part A: Syst. Humans 38 (2008) 698-714.

[4] J.L. Hueso, E. Martínez, C. Teruel, Convergence, effiency and dinamimics of new fourth and sixth order families of iterative methods for nonlinear systems, Comput. Appl. Math. 275 (2015) 412-420.

[5] Y. Khan, M. Fardi, K. Sayevand, A new general eighth-order family of iterative methods for solving nonlinear equations, Appl. Math. Letters 25 (2012) 2262-2266.

[6] R.F. Lin, H.M. Ren, Z. Šmarda, Q.B. Wu, Y. Khan, J.L. Hu, New families of thrid-order iterative methods for finding multiple roots, Appl. Math. 2014 (2014), ID 812072, 9 pages.

[7] H. Montazeri, F. Soleymani, S. Shateyi, S.S. Motsa, On a new method for computing the numerical solution of systems of nonlinear equations, Appl. Math. 2012 (2012) Article ID. 751975, 15 pages.

[8] F. Soleymani, T. Lofti, P. Bakhtiari, A multistep class of iterative methods for nonlinear systems, Optim. Letters 8 (2014) 1001-1015.

[9] X. Wang, T. Zhang, W. Qian, M. Teng, Seventh-order derivative-free iterative method for solving nonlinear systems, Numer. Algor. 70 (2015) 545-558.

[10] , X.Y. Xiao, H.W. Yin, Increasing the order of convergence for iterative methods to solve nonlinear systems, Calcolo, DOI 10.1007/s10092-015-0149-9.

[11] J.M. Ortega, W.C. Rheinboldt, Iterative Solution of Nonlinear Equations in Several Variables, Academic Press, New York, 1970.

[12] F.I. Chicharro, A. Cordero, J.M. Gutiérrez, J.R. Torregrosa, Complex dynamics of derivative-free methods for nonlinear equations, Appl. Math. Comput. 219 (2013) 7023-7035.

[13] A. Cordero, F. Soleymani, J.R. Torregrosa, S. Shateyi, Basins of attractionfor various Steffensen-type methods, Appl. Math. 2014 (2014), ID 539707, 17 pages.

[14] S. Amat, S. Busquier, On a Steffensen's type method and its behavior for semismooth equations, Appl. Math. Comput. 177 (2006) 819-823.

[15] A.M. Ostrowski, Solutions of Equations and Systems of Equations, Academic Press, New York, London, 1966.

[16] M.F. Abad, A. Cordero, J. R. Torregrosa, A family of seventh-order schemes for solving nonlinear systems, Bull. Math. Soc. Sci. Math. Roumanie 57(105) No. 2 (2014) 133-145.

[17] A. Cordero, J. García-Maimó, J.R. Torregrosa, M.P. Vassileva, Solving nonlinear problems by Ostrowski-Chun type parametric families, Math. Chem. 53 (2015) 430-449.

[18] P. Jarratt, Some fourth order multipoint iterative methods for solving equations, Math. Comp., 20 (1966) 434-437.

[19] J.R. Sharma, H. Arora, On efficient weighted-Newton methods for solving systems of nonlinear equations, Appl. Math. Comput., 222 (2013) 497-506.

[20] H. Montazeri, F. Soleymani, S. Shateyi, S. S. Motsa, On a New Method for Computing the Numerical Solution of Systems of Nonlinear Equations, J. Appl. Math, 2012 (2012) Article ID 751975, 15 pages.

[21] J.L. Hueso, E. Martínez, C. Teruel, Convergence, efficiency and dynamics of new fourth and sixth order families of iterative methods for nonlinear systems, J. Comput. Appl. Math., 275 (2015) 412-420.

${ }_{245}^{2422] ~ J . R . ~ S h a r m a, ~ H . ~ A r o r a, ~ I m p r o v e d ~ N e w t o n-l i k e ~ m e t h o d s ~ f o r ~ s o l v i n g ~ s y s t e m s ~ o f ~ n o n l i n e a r ~ e q u a t i o n s, ~}$ SeMA Journal., 74 (2016) 1-7. 
[23] A. Cordero, E. Gómez, J.R. Torregrosa, Efficient High-Order Iterative Methods for Solving Nonlinear Systems and Their Application on Heat Conduction Problems, Complexity, Vol. 2017, Article ID 6457532, 11 pages (2017).

[24] A. Cordero, J.R. Torregrosa, Low-complexity root-finding iteration functions with no derivatives of any order of convergence, J. Comput. Appl. Math., 275 (2015) 205-515.

[25] A. Cordero, J.L. Hueso, E. Martínez, J.R. Torregrosa, A modified Newton-Jarratt's composition, Numer. Algor., 55 (2010) 87-99.

[26] A. Cordero, J.R. Torregrosa, Variants of Newton's method using fifth-order quadrature formulas, Appl. Math. Comput., 190 (2007) 686-698. 